\title{
Approaches to the diagnosis and management of patients with a history of nonsteroidal anti-inflammatory drug-related urticaria and angioedema
}

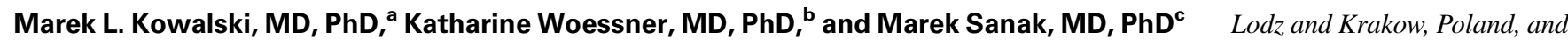

La Jolla, Calif

Nonsteroidal anti-inflammatory drug (NSAID)-induced urticarial and angioedema reactions are among the most commonly encountered drug hypersensitivity reactions in clinical practice. Three major clinical phenotypes of NSAIDinduced acute skin reactions manifesting with angioedema, urticaria, or both have been distinguished: NSAIDexacerbated cutaneous disease, nonsteroidal anti-inflammatory drug-induced urticaria/angioedema (NIUA), and single NSAID-induced urticaria and angioedema. In some patients clinical history alone might be sufficient to establish the diagnosis of a specific type of NSAID hypersensitivity, whereas in other cases oral provocation challenges are necessary to confirm the diagnosis. Moreover, classification of the type of cutaneous reaction is critical for proper management. For example, in patients with single NSAIDinduced reactions, chemically nonrelated COX-1 inhibitors can be safely used. However, there is cross-reactivity between the NSAIDs in patients with NSAID-exacerbated cutaneous disease and NIUA, and thus only use of selective COX-2 inhibitors can replace the culprit drug if the chronic treatment is necessary, although aspirin desensitization will allow for chronic treatment with NSAIDs in some patients with NIUA. In this review we present a practical clinical approach to the patient with NSAID-induced urticaria and angioedema. (J Allergy Clin Immunol 2015;136:245-51.)

Key words: Aspirin, angioedema, nonsteroidal anti-inflammatory drugs, urticaria

Aspirin and other nonsteroidal anti-inflammatory drugs (NSAIDs) are second after antibiotics as the most common cause of drug-induced hypersensitivity reactions, affecting approximately $1 \%$ to $3 \%$ of the general population. However, in populations such as those with chronic rhinosinusitis, asthma, or chronic urticaria, the prevalence of NSAID hypersensitivity might

From ${ }^{\mathrm{a} D e p a r t m e n t}$ of Immunology, Rheumatology and Allergy, Medical University of

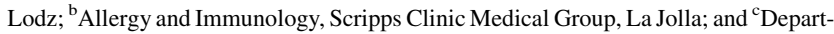
ment of Medicine, Jagiellonian University Medical College, Krakow.

Disclosure of potential conflict of interest: $\mathrm{K}$. Woessner has consultant arrangements with and has received payments for lectures from Merck, TEVA, Shire, Meda, and AstraZeneca. The rest of the authors declare that they have no relevant conflicts of interest.

Received for publication March 3, 2015; revised June 9, 2015; accepted for publication June 12, 2015.

Corresponding author: Marek L. Kowalski, MD, PhD, Medical University of Lodz, Department of Clinical Immunology and Allergy, Rheumatology and Allergy, 251 Pomorska Str, Lodz 92-213, Poland. E-mail: Marek.Kowalski@ csk.umed.lodz.pl. 0091-6749/\$36.00

(C) 2015 American Academy of Allergy, Asthma \& Immunology

http://dx.doi.org/10.1016/j.jaci.2015.06.021
Abbreviations used

ASA: Acetylsalicylic acid

NECD: Nonsteroidal anti-inflammatory drug-exacerbated cutaneous disease

NIUA: Nonsteroidal anti-inflammatory drug-induced urticaria/ angioedema

NSAID: Nonsteroidal anti-inflammatory drug

SNIUAA: Single nonsteroidal anti-inflammatory drug-induced urticaria/angioedema, anaphylaxis, or both

be even higher, affecting up to $20 \%$ to $30 \%$. $^{1,2}$ NSAID hypersensitivity reactions can be associated with multiple symptoms ranging in severity from transient rash to severe anaphylaxis, with the majority of reactions limited to the skin. ${ }^{3-5}$ NSAIDinduced skin reactions usually develop within hours (rarely within minutes) after drug intake, manifesting as urticarial wheals, angioedema, or erythema multiforme. Less frequently observed are NSAID-triggered delayed skin reactions occurring more than 24 hours after dosing and manifest as either skin-specific (eg, exanthema, fixed drug eruption, toxic epidermal necrolysis, or Stevens-Johnsons syndrome) or other organspecific manifestations (eg, aseptic meningitis or hypersensitivity pneumonitis). ${ }^{6}$

The purpose of this review is to present a practical clinical approach to the diagnosis and management of cutaneous reactions to aspirin and other NSAIDs.

\section{CLASSIFICATION OF NSAID REACTIONS}

The current classification of NSAID hypersensitivity reactions is based on timing, the clinical pattern of symptoms, and the presence or absence of cross-reactivity to other NSAIDs. ${ }^{7-9}$ An additional criterion is the presence of underlying chronic disease of the skin or respiratory tract, which is typical for some $(10$ crossreactive types) but not all (single drug-induced type) reactions (Table I).

Using this classification system, a physician can assess the putative pathomechanism of a reaction (allergic or nonallergic) related to the presence or absence of cross-reactivity at an early stage of the diagnostic process. ${ }^{11}$ In the majority of patients, the mechanism of NSAID-induced skin symptoms occurs through the pharmacologic activity of aspirin and other NSAIDs through inhibition of the COX-1 enzyme. In susceptible subjects COX-1 inhibition results in the activation of inflammatory cells, which generate inflammatory mediators. ${ }^{10}$ These patients react to both aspirin and other chemically nonrelated NSAIDs (COX-1 inhibitors), and thus this type of hypersensitivity has been called crossreactive. In patients with a history of reactions to a single NSAID 
TABLE I. Current classification of aspirin and NSAID-induced reactions ${ }^{8}$

\begin{tabular}{|c|c|c|c|c|c|}
\hline Type of reaction & Clinical manifestation & $\begin{array}{l}\text { Timing of } \\
\text { reaction }\end{array}$ & Underlying disease & Cross-reactive & Putative mechanism \\
\hline $\begin{array}{l}\text { NSAID-exacerbated } \\
\text { respiratory disease (NERD) }\end{array}$ & Respiratory & Acute & Asthma/rhinosinusitis & Cross-reactive & COX-1 inhibition \\
\hline NIUA & Cutaneous & & No or atopy & & Probably COX-1 inhibition \\
\hline SNIUAA & Cutaneous/anaphylaxis & & No & Non-cross-reactive & IgE mediated \\
\hline $\begin{array}{l}\text { Single NSAID-induced } \\
\text { delayed reactions (SNIDR) }\end{array}$ & $\begin{array}{l}\text { Various symptoms and organs } \\
\text { involved }\end{array}$ & Delayed onset & No & & $\mathrm{T}$ cell mediated \\
\hline
\end{tabular}

Types of reactions manifesting primarily as urticaria/angioedema are shown in boldface.

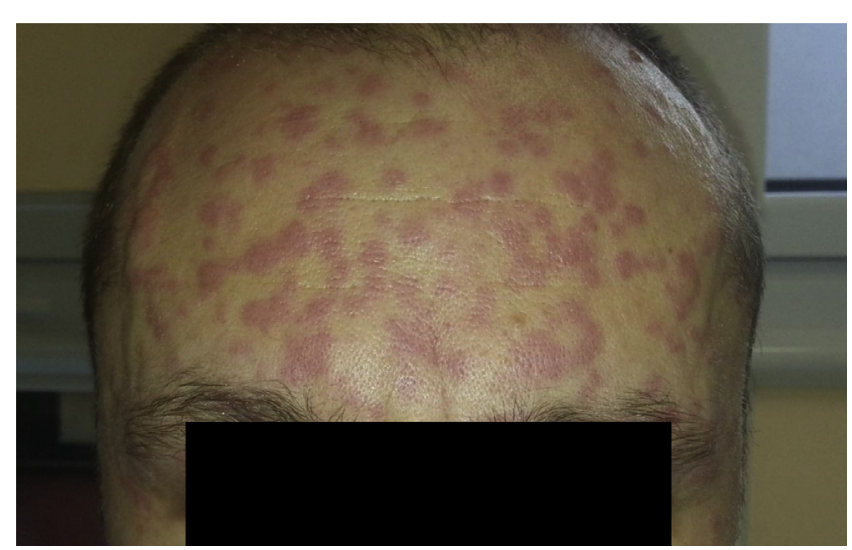

FIG 1. Patient with a history of chronic spontaneous urticaria exacerbated by ibuprofen and paracetamol (NECD) who had acute urticarial lesions 60 minutes after oral challenge with $117 \mathrm{mg}$ of aspirin.

who are otherwise tolerant of other NSAIDs, including aspirin, an immunologic IgE-mediated mechanism can be suspected, and these patients could be called single-drug reactors.

Three major clinical phenotypes of hypersensitivity reactions to aspirin and other NSAIDs manifesting as urticaria, angioedema, or both can be distinguished.

\section{NSAID-EXACERBATED CUTANEOUS DISEASE}

Patients with chronic urticaria who experience hypersensitivity reactions to NSAIDs are now identified as having aspirin-exacerbated cutaneous disease or, more precisely, nonsteroidal anti-inflammatory drug-exacerbated cutaneous disease (NECD). ${ }^{8}$

\section{Clinical presentation}

Approximately $12 \%$ to $30 \%$ of patients with chronic spontaneous urticaria will experience an exacerbation of their skin symptoms within minutes to 4 hours when exposed to COX-1inhibiting NSAIDs (Fig 1). ${ }^{12,13}$ In some patients the sensitivity to NSAIDs might precede the development of chronic urticaria. ${ }^{14}$ Analogous to patients with aspirin-exacerbated respiratory disease, they react to all COX-1-inhibiting NSAIDs, and despite the avoidance of NSAIDs, the underlying disease process continues (ie, avoidance of NSAIDs will not lead to resolution of chronic urticaria). ${ }^{15}$ On the contrary, the highly selective COX-2 inhibitors are typically well tolerated in this patient population. $^{16,17}$

\section{Pathogenesis}

NECD is the cutaneous corollary of NSAID-exacerbated respiratory disease in that reactions are triggered by NSAIDs with COX-1 inhibitory activity in doses reflecting their in vitro inhibitory potency against COX-1 isoenzyme. ${ }^{18}$ In patients with NECD, the inhibition of COX-1 enzyme leads to the release of cysteinyl leukotrienes by inflammatory cells. ${ }^{15}$

Various inflammatory cells and markers are activated in patients with NECD, leading to the hypersensitivity reaction. At baseline, these patients have increased urinary leukotriene $\mathrm{E}_{4}$ levels, which are further increased during a positive drug challenge. ${ }^{19}$ Additionally, it has been shown that degranulation of basophils in patients with NECD is enhanced. ${ }^{20}$ A mechanism that might trigger the activation of inflammatory cells is the inhibition of prostaglandin $\mathrm{E}_{2}\left(\mathrm{PGE}_{2}\right)$ synthesis. $\mathrm{PGE}_{2}$, which acts through the EP2 receptor, stabilizes mast cells, and therefore the abrupt decrease in $\mathrm{PGE}_{2}$ levels that occurs with COX-1 inhibition might lead to mediator release from inflammatory cells and the development of symptoms in susceptible subejcts. ${ }^{21}$ Furthermore, aspirin can increase Syk kinase phosphorylation of the FceRI signaling complex, facilitating mast cell activation. ${ }^{22}$ Increased mast cell reactivity might also be related to a genetic predisposition because of a variant of the FceRI $\alpha$ subunit gene (FCER $1 A-344 \mathrm{C}>\mathrm{T})$, which is more common among patients with NECD. ${ }^{23}$ Moreover, the role of autoimmunity in these reactions has been postulated ${ }^{24}$ because a positive autologous serum skin test result ${ }^{25}$ or autologous plasma skin test result ${ }^{26}$ can distinguish NECD from single NSAID-induced urticaria/angioedema. To what extent platelets are involved in the pathogenesis of NECD remains to be established. ${ }^{27,28}$

\section{Diagnosis}

The diagnosis of NECD first requires confirmation of the diagnosis of chronic urticaria, which by definition is the spontaneous development of urticaria that has been continuously or intermittently present for at least 6 weeks. ${ }^{29}$ A careful history can confirm the diagnosis of NECD if the patient has previously reacted to NSAIDs or acetylsalicylic acid (ASA) with exacerbation of their underlying chronic urticaria. An aspirin or other specific NSAID challenge is the gold standard for determination of NECD. A single-blind, placebo-controlled 2-day aspirin challenge can be performed after the patient has been without any skin eruptions for 1 to 2 weeks. ${ }^{30}$ On day 1 , the patient receives a placebo to determine baseline activity, and on day 2, the patient receives escalating doses of $\operatorname{ASA}(71,117,312$, and $500 \mathrm{mg})$ at 1.5- to 2-hour intervals. ${ }^{31}$ Most patients will react to a single 
TABLE II. NSAID classes determined by similar chemical structures

\begin{tabular}{ll}
\hline Chemical class & \multicolumn{1}{c}{ Drugs } \\
\hline $\begin{array}{l}\text { Salicylic acid derivatives } \\
\text { Propionic acid derivatives (profens) }\end{array}$ & Aspirin (ASA), sodium salicylate, choline magnesium trysalicylate, salsalate, diflunisal, sufasalazine, olsalazine \\
Acetic acid derivatives & Ibuprofen, dexibuprofen, naproxen, fenoprofen, ketoprofen, dexketoprofen, flurbiprofen, oxaprozin, loxoprofen \\
Pyrazolic derivatives (pyrazolones) & Indomethacin, tolmetin, sulindac, etodolac, ketorolac, diclofenac, aceclofenac, nabumetone \\
& $\begin{array}{c}\text { Metamizole, phenylbutazone, phenazone, aminophenazone, ampyrone, suxibuzone, sulfamazone, nifenazone, } \\
\text { pyrazolone, propyphenazone }\end{array}$ \\
Anthranilic acid derivatives (fenamates) & Mefenamic acid, flufenamic acid, tolfenamic acid \\
Enolic acid derivatives (oxicams) & Piroxicam, meloxicam, tenoxicam, droxicam, lornoxicam, isoxicam \\
Para-aminophenol derivatives & Acetaminophen, paracetamol \\
\hline
\end{tabular}

dose of aspirin between 325 and $650 \mathrm{mg}$, with at least 1 hour to react after ingestion of aspirin. There is no role for skin testing in the diagnosis of NECD.

\section{NSAID-INDUCED URTICARIA/ANGIOEDEMA}

Aspirin and other NSAIDs can also induce urticaria, angioedema, or both in an otherwise healthy subject without a history of pre-existing chronic skin disease (eg, spontaneous urticaria).

\section{Clinical presentation}

The skin reaction usually appears within 1 hour of oral drug intake, but in some patients it can develop within 1 to 6 hours. Although in most situations urticaria and angioedema appear simultaneously, NSAID-induced angioedema without urticaria (specifically after ibuprofen and diclofenac) has been seen. ${ }^{32}$ Concomitant anaphylactic reactions have also been reported. ${ }^{33}$ Up to $60 \%$ of patients with nonsteroidal anti-inflammatory druginduced urticaria/angioedema (NIUA) have atopic diseases (rhinitis and asthma), and positive immediate-type skin test responses to inhalant allergens (Dermatophagoides farinae and Dermatophagoides pteronyssinus) are common among these patients. ${ }^{34,35}$ Furthermore, NSAID hypersensitivity in patients without a history of chronic urticaria can also manifest as isolated periorbital angioedema. ${ }^{32,36,37}$ Among patients with NSAIDinduced isolated periorbital angioedema, sensitization to house dust mite allergen is common as well, suggesting that it might be a subtype of NIUA. ${ }^{38,39}$ Earlier observations have proposed that NIUA can precede the appearance of chronic spontaneous urticaria by years ${ }^{14}$; however, a more recent study documented that the percentage of patients with NIUA having chronic spontaneous urticaria is not different from that among healthy control subjects. ${ }^{40}$

\section{Pathogenesis}

Patients with NIUA cross-react to chemically nonrelated NSAIDs, and thus a similar mechanism of hypersensitivity related to $\mathrm{COX}-1$ inhibition is proposed. A variant of leukotriene $\mathrm{C}_{4}$ synthase (LTC4-444A $>$ C) doubled the odds ratio for NIUA in one study, although such an association was not found in any other population. ${ }^{41,42}$ Together with another study documenting the association of NIUA with a thromboxane synthase polymorphism (TBXAS1 rs6962291), ${ }^{43}$ these data strongly support the COX-1 inhibition-related mechanism of reaction. However, as mentioned above, aeroallergen sensitization is common in patients with NIUA and might even be a prerequisite for the development of NSAID hypersensitivity. ${ }^{33,44,45}$ Thus the role of underlying atopy and IgE-related mechanisms remains to be established.

\section{Diagnosis}

A history of skin reactions to at least 2 NSAIDs with different chemical structures in patients without underlying chronic cutaneous disease have been shown to have high sensitivity for the diagnosis of NIUA. ${ }^{46,47}$ If the history is not clear and aspirin was not a culprit drug, an oral challenge with aspirin is recommended to confirm a cross-reactive type of NSAID hypersensitivity and to help differentiate NIUA from single NSAID-induced urticaria/angioedema. As in other cross-reactive types of NSAIDs, hypersensitivity skin testing with a culprit drug or drug-specific IgE in serum are not useful and hence not indicated.

\section{SINGLE NSAID-INDUCED URTICARIA/ ANGIOEDEMA, ANAPHYLAXIS, OR BOTH}

Wheals, angioedema, and/or anaphylaxis induced by a single NSAID or by 2 or more NSAIDs with similar chemical structures (ie, belonging to the same chemical group; Table II) are typical for this type of NSAID hypersensitivity. ${ }^{48}$

\section{Clinical presentation}

The most common symptoms are urticaria and angioedema, but in about one third of patients, anaphylaxis can develop, which could result in death. ${ }^{33,49}$ Symptoms can develop within minutes after drug injection or up to 1 hour after oral intake of the drug. Although almost all NSAIDs are capable of inducing this type of reaction, pyrazolones seem to be the most common triggers of single nonsteroidal anti-inflammatory drug-induced urticaria/angioedema, anaphylaxis, or both (SNIUAA [in countries where the drug is still used]), followed by diclofenac and paracetamol. $^{50-52}$

\section{Pathogenesis}

In the majority of patients, symptoms develop within minutes, typically less than 30 minutes, suggesting an immunologic IgErelated mechanism. ${ }^{53}$ Patients tolerate chemically nonrelated NSAIDs well, even if they are potent COX-1 inhibitors. In a significant proportion of patients with SNIUAA, IgE specific to a culprit drug can be detected either by means of skin testing or immunoassays in serum. ${ }^{48}$ However, the pathomechanism of these reactions seems to be more complex because hapten modification of human serum albumin by NSAIDs in patients with SNIUAA was found. Moreover, a glucuronide acyl modification of different lysine residues of albumin was reported for diclofenac, ketoprofen, and acetaminophen. ${ }^{54,55}$ In vitro prediction of an SNIUAA reaction on this basis is not yet feasible. 


\begin{tabular}{|c|c|c|c|}
\hline $\begin{array}{l}\text { Spectrum of } \\
\text { symptoms }\end{array}$ & \multicolumn{2}{|c|}{$\begin{array}{c}\text { Urticaria/ } \\
\text { angioedema }\end{array}$} & $\begin{array}{l}\text { Urticaria/ angioedema } \\
\text { and/or anaphylaxis }\end{array}$ \\
\hline Onset of reaction & \multicolumn{2}{|c|}{ 1hour to 6 hours } & Minutes to 1 hour \\
\hline $\begin{array}{l}\text { History of cross- } \\
\text { reactivity }\end{array}$ & \multicolumn{2}{|c|}{$\begin{array}{l}\text { Reactions to several } \\
\text { Cox-1 inhibitors }\end{array}$} & Reactions to single NSAID \\
\hline $\begin{array}{l}\text { Underlying } \\
\text { chronic disorder }\end{array}$ & $\begin{array}{l}\text { Chronic } \\
\text { urticaria }\end{array}$ & $\begin{array}{l}\text { Usually no } \\
\text { or atopy }\end{array}$ & Usually No \\
\hline Type of reaction & NECD & NIUA & SNIUAA \\
\hline Putative mechanisms & \multicolumn{2}{|c|}{ Non-immunological } & Immunological \\
\hline $\begin{array}{l}\text { Skin testing or serum } \\
\text { IgE }\end{array}$ & \multicolumn{2}{|c|}{ Not relevant } & May be diagnostic \\
\hline $\begin{array}{l}\text { Oral challenge with } \\
\text { aspirin }\end{array}$ & \multicolumn{2}{|c|}{ To confirm cross-reactive type } & $\begin{array}{c}\text { To exlude cross-reactive } \\
\text { type }\end{array}$ \\
\hline $\begin{array}{l}\text { Oral challenge with } \\
\text { culprit NSAID }\end{array}$ & \multicolumn{2}{|c|}{ Yes } & Not recommended \\
\hline
\end{tabular}

FIG 2. Diagnosis of urticaria/angioedema induced by NSAIDs.

\section{Diagnosis}

These patients usually react to other members of the same drug family and are tolerant of other chemically unrelated NSAIDs (Table II). ${ }^{52}$ The most reliable way to make the diagnosis of SNIUAA and exclude a cross-reactive type would be an oral challenge with aspirin. Tolerance of aspirin confirms a single drug type of hypersensitivity. Because the putative mechanism of SNIUAA involves IgE, skin testing with the culprit drug o identification of serum specific IgE is justified. Positive skin test results have been reported in most patents with a history of reactions to pyrazolone derivates ${ }^{49,50,56}$; however, the timing of testing after the reaction might be important because skin test reactivity subsides within a year of the reaction. The reliability of routine skin testing to other NSAIDs (including propionic acid derivatives) has not been documented in systematic studies, and there are no standardized protocols for nonpyrazolone NSAIDs. ${ }^{57}$ The usefulness of drug-specific IgE detection in serum has not been well documented, and immunoassays are not commercially available. Although the diagnostic utility of a basophil activation test has been reported, these tests have not been validated and require further studies. ${ }^{58}$

\section{MIXED REACTIONS}

Although the vast majority of NSAID-induced acute (within 24 hours) skin reactions can fall into one of the 3 phenotypes presented by the current classification, some patients can manifest atypical or blended reactions. Approximately $10 \%$ of patients with NECD will have respiratory symptoms (bronchoconstriction) resembling the reactions observed in patients with NSAIDexacerbated respiratory disease. ${ }^{59}$ In a study by Doña et al, ${ }^{33}$ who reviewed 384 patients with NSAID-induced skin reactions, concomitant respiratory symptoms were reported by $18.2 \%$ of patients with cross-reactive reactions (patients with NIUA) and $4.6 \%$ of patients with single-drug reactions (patients with SNIUAA). Association of rhinoconjunctivitis with NSAIDinduced skin reactions has been also reported. ${ }^{60}$

\section{DIAGNOSTIC ALGORITHM}

Diagnosis of a specific type of hypersensitivity is a prerequisite for proper management of a patient with a history of NSAID hypersensitivity. Based on the current classification, a practical diagnostic algorithm to determine the type of NSAID hypersensitivity has been proposed ${ }^{8,61}$ and can be easily adapted when hypersensitivity is manifested with cutaneous symptoms (urticaria/ angioedema, Fig 2). Although a detailed analysis of the patient's history might be sufficient to establish the diagnosis of a specific type of NSAID hypersensitivity, it is associated with relatively low specificity. ${ }^{62}$ In a study by Viola et al, ${ }^{63}$ as many as $78.8 \%$ of patients with a historical reaction to an NSAID tolerated that NSAID in an oral challenge. Thus if the history is not strong, oral provocation challenges might be necessary to avoid overdiagnosis. ${ }^{64}$ Currently, there is limited evidence for the use of in vitro testing.

\section{MANAGEMENT}

Once the diagnosis of NSAID hypersensitivity has been established, the mainstay of treatment is avoidance of NSAIDs. ${ }^{7,65}$ However, recommendations for management and alternative NSAIDs have to be tailored to a specific type of NSAID hypersensitivity (Table III). ${ }^{66}$ 
TABLE III. Recommendations for management of patients with NSAID-induced urticaria/angioedema

\begin{tabular}{llll}
\hline & \multicolumn{1}{c}{ NCED } & NIUA & SNIUAA \\
\hline $\begin{array}{l}\text { Type of reaction } \\
\text { NSAIDs to be avoided }\end{array}$ & $\begin{array}{l}\text { Cross-reactive } \\
\text { All preferential COX-1 inhibitors }\end{array}$ & $\begin{array}{l}\text { Cross-reactive } \\
\text { All preferential COX-1 inhibitors }\end{array}$ & $\begin{array}{c}\text { Single drug; selective (IgE mediated) } \\
\text { All NSAIDs with similar chemical structure } \\
\text { (same chemical class) }\end{array}$ \\
NSAIDs recommended & Selective COX-2 inhibitor* & Selective COX-2 inhibitors* & $\begin{array}{c}\text { All NSAIDs with different chemical } \\
\text { structures (different chemical class) }\end{array}$ \\
Aspirin desensitization & $\begin{array}{l}\text { Feasible } \\
\text { Not recommended }\end{array}$ & $\begin{array}{l}\text { Feasible } \\
\text { Recommended if avoidance is not possible } \\
\text { (eg, treatment with aspirin in patients with } \\
\text { cardiovascular disease) }\end{array}$ & Not recommended \\
& & &
\end{tabular}

*Oral office challenge with an alternative NSAID is recommend.

\section{NECD}

The highly selective COX-2 inhibitors (celecoxib and etoricoxib) are generally well tolerated in this patient population. ${ }^{16}$ There have been rare reports of these patients reacting to the COX-2 inhibitors, and therefore it is recommended that provocation tests for these drugs be performed in a controlled setting to confirm their tolerability. ${ }^{13,67}$ In some patients with NECD, low-dose ASA ( $81 \mathrm{mg}$ ) can be tolerated because it is usually less than the provoking dose. Furthermore, use of leukotrienemodifying drugs might be of benefit in conjunction with standard chronic urticaria management in patients with NECD. ${ }^{68}$

Aspirin desensitization is not recommended in these patients. Although several case reports of successful desensitization have been reported, for the most part, the urticaria becomes intractable with continued attempts at aspirin exposure, leading to failure to achieve a desensitized state. ${ }^{69}$

\section{NIUA}

Avoidance of the culprit drug and potentially cross-reactive compounds (COX-1 inhibitors) would usually prevent recurrence of urticaria/angioedema symptoms. However, if chronic intake of aspirin (eg, for cardiovascular disease) or other strong COX-1 inhibitors (eg, for osteoarthritis) is necessary, desensitization to aspirin can be performed because several protocols for desensitization are available. ${ }^{61,70,71}$

\section{SNIUAA}

In a patient with hypersensitivity to a single NSAID (eg, diclofenac, ibuprofen, or ketoprofen), when the culprit drug has been identified, it can be replaced easily by another NSAID with an unrelated chemical structure but similar anti-inflammatory potency (Table II). Desensitization is not recommended.

\section{CONCLUSIONS AND SUGGESTIONS FOR FUTURE WORK}

In susceptible subjects urticaria, angioedema, or both develop after NSAID intake, usually within hours (rarely within minutes). Physicians can follow a simple algorithm based on current classification, leading to diagnosis of the type of NSAID hypersensitivity. Identification of the specific type of hypersensitivity allows for identification of the proper management options. However, because the history of NSAID hypersensitivity is not very specific, in many instances an oral challenge test with the culprit drug might be necessary to confirm the diagnosis or an oral challenge test with aspirin might be necessary for assessment of cross-tolerance.

It is essential to continue research on the validation of already available in vitro tests (eg, immunoassays for drug-specific IgE or basophil activation tests) and on the development of new tests, possibly based on genetic analysis. ${ }^{72}$ Future studies with highthroughput technology should allow for improvement in our understanding of pathomechanisms, better definition of current clinical phenotypes, and potential identification of emerging new phenotypes of NSAID hypersensitivity. ${ }^{73,74}$

\section{REFERENCES}

1. Schubert B, Grosse Perdekamp MT, Pfeuffer P, Raith P, Bröcker EB, Trautmann A. Nonsteroidal anti-inflammatory drug hypersensitivity: fable or reality? Eur J Dermatol 2005;15:164-7.

2. Hedman J, Kaprio J, Poussa T. Prevalence of asthma, aspirin intolerance, nasal polyposis and chronic obstructive pulmonary disease in a population-based study. Int J Epidemiol 1999;28:717-22.

3. Sánchez-Borges M, Capriles-Hulett A, Caballero-Fonseca F. NSAID-induced urticaria and angioedema: a reappraisal of its clinical management. Am J Clin Dermatol 2002:3:599-607.

4. Aun MV, Blanca M, Garro LS, Ribeiro MR, Kalil J, Motta AA, et al. Nonsteroidal anti-inflammatory drugs are major causes of drug-induced anaphylaxis J Allergy Clin Immunol Pract 2014;2:414-20.

5. Park H-S, Kowalski ML, Sanchez-Borges M. Hypersensitivity to aspirin and other non-steroidal antiinflammatory drugs. In: Adkinson NF Jr, Bochner BS, Burks AW, Busse WW, Holgate ST, Lemanske RF Jr, editors. Middleton's allergy principles and practice. 8th ed. Philadelphia: Elsevier; 2013. pp. 1296-309.

6. Torres MJ, Mayorga C, Blanca M. Nonimmediate allergic reactions induced by drugs: pathogenesis and diagnostic tests. J Investig Allergol Clin Immunol 2009; 19:80-90.

7. Stevenson DD, Sanchez-Borges M, Szczeklik A. Classification of allergic and pseudoallergic reactions to drugs that inhibit cyclooxygenase enzymes. Ann Allergy Asthma Immunol 2001;87:177-80.

8. Kowalski ML, Asero R, Bavbek S, Blanca M, Blanca-Lopez N, Bochenek G, et al. J. Classification and practical approach to the diagnosis and management of hypersensitivity to nonsteroidal anti-inflammatory drugs. Allergy 2013;68: 1219-32.

9. Kowalski ML, Stevenson DD. Classification of reactions to nonsteroidal antiinflammatory drugs. Immunol Allergy Clin North Am 2013;33:135-45.

10. Szczeklik A, Stevenson DD. Aspirin-induced asthma: advances in pathogenesis, diagnosis, and management. J Allergy Clin Immunol 2003;111:913-22.

11. Kowalski ML, Makowska JS, Blanca M, Bavbek S, Bochenek G, Bousquet J, et al. Hypersensitivity to nonsteroidal anti-inflammatory drugs (NSAIDs) —classification, diagnosis and management: review of the EAACI/ENDA(\#) and GA2LEN/HANNA*. Allergy 2011;66:818-29.

12. Szczeklik A, Gryglewski RJ, Czerniawska-Mysik G. Clinical patterns of hypersensitivity to nonsteroidal anti-inflammatory drugs and their pathogenesis J Allergy Clin Immunol 1977;60:276-84.

13. Sanchez-Borges M, Caballero-Fonseca F, Capriles-Hulett A, Gonzalez-Aveledo L. Aspirin-exacerbated cutaneous disease (AECD) is a distinct subphenotype of chronic spontaneous urticaria. J Eur Acad Dermatol Venereol 2015;29:698-701.

14. Asero R. Intolerance to nonsteroidal anti-inflammatory drugs might precede by years the onset of chronic urticaria. J Allergy Clin Immunol 2003;111:1095-8. 
15. Mastalerz L, Setkowicz M, Szczeklik A. Mechanism of chronic urticaria exacerbation by aspirin. Curr Allergy Asthma Rep 2005;5:277-83.

16. Zembowicz A, Mastalerz L, Setkowicz M, Radziszewski W, Szczeklik A. Safety of cyclooxygenase 2 inhibitors and increased leukotriene synthesis in chronic idiopathic urticaria with sensitivity to nonsteroidal anti-inflammatory drugs Arch Dermatol 2003;139:1577-82.

17. Asero R. Etoricoxib challenge in patients with chronic urticaria with NSAID intolerance. Clin Exp Dermatol 2007:32:661-3.

18. Patrignani P, Patrono C. Cyclooxygenase inhibitors: from pharmacology to clinical read-outs. Biochim Biophys Acta 2014;1851:422-32.

19. Mastalerz L, Setkowicz M, Sanak M, Szczeklik A. Hypersensitivity to aspirin common eicosanoid alterations in urticaria and asthma. J Allergy Clin Immunol $2004 ; 113: 771-5$

20. Hsieh C-W, Lee J-W, Liao E-C, Tsai J-J. A disease marker for aspirin-induced chronic urticaria. Int J Mol Sci 2014;15:12591-603.

21. Torres R, Picado C, de Mora F. The PGE2-EP2-mast cell axis: an antiasthma mechanism. Mol Immunol 2015;63:61-8.

22. Matsuo H, Yokooji T, Morita H, Ooi M, Urata M, Urata K, et al. Aspirin augments IgE-mediated histamine release from human peripheral basophils via Syk kinase activation. Allergol Int 2013;62:503-11.

23. Bae JS, Kim SH, Yoon HJ, Suh CH, Nahm DH, Park HS. Significant association of FceRI $\alpha$ promoter polymorphism with aspirin-intolerant chronic urticarial. J Allergy Clin Immunol 2007:119:449-56.

24. Posthumus J, TiIñana A, Mozena JD, Steinke JW, Borish L. Autoimmune mech anism in chronic idiopathic urticaria. J Allergy Clin Immunol 2012;130:814-6.

25. Erbagzi Z. Multiple NSAID intolerance in chronic idiopathic urticarial is correlated with delayed, pronounced and prolonged autoreactivity. J Dermatol 2004 31:376-82.

26. Asero R. Predictive value of autologous plasma skin test for multiple nonsteroidal anti-inflammatory drug intolerance. Int Arch Allergy Immunol 2007;144:226-30.

27. Palikhe S, Palikhe NS, Kim SH, Yoo HS, Shin YS, Park HS. Elevated platelet activation in patients with chronic urticarial: a comparison between aspirinintolerant and aspirin-tolerant groups. Ann Asthma Allergy Immunol 2014;113: 276-81.

28. Laidlaw TM, Kidder MS, Bhattacharyya N, Xing W, Shen S, Milne GL, et al. Cysteinyl leukotriene overproduction in aspirin-exacerbated respiratory disease by platelet-adherent leukocytes. Blood 2012;119:3790-8.

29. Bernstein JA, Lang DM, Khan DA, Craig T, Dreyfus D, Hsieh F, et al. The diagnosis and management of acute and chronic urticaria: 2014 update. J Allergy Clin Immunol 2014;133:1270-7.

30. Nizankowska-Mogilnicka E, Bochenek G, Mastalerz L, Swierczynska M, Picado C, Scadding G, et al. EAACI/GA2LEN guideline: aspirin provocation tests for diagnosis of aspirin hypersensitivity. Allergy 2007;62:1111-8.

31. Rajan JP, Simon RA, Bosso JV. Prevalence of sensitivity to food and drug additives in patients with chronic idiopathic urticaria. J Allergy Clin Immunol Pract 2014;2:168-71.

32. Leeyaphan C, Kulthanan K, Jongjarearnprasert K, Dhana N. Drug-induced angioedema without urticaria: prevalence and clinical features. J Eur Acad Dermatol Venereol 2010;24:685-91.

33. Doňa I, Blanca-López N, Cornejo-Garcia JA, Torres MJ, Laguna JJ, Fernández J, et al. Characteristics of subjects experiencing hypersensitivity to non-steroida anti-inflammatory drugs: patterns of response. Clin Exp Allergy 2011;41:86-95.

34. Doña I, Blanca-López N, Torres MJ, García-Campos J, García-Núñez I, Gómez F, et al. Drug hypersensitivity reactions: response patterns, drug involved, and temporal variations in a large series of patients. J Investig Allergol Clin Immunol 2012:22:363-71.

35. Sánchez-Borges M, Acevedo N, Caraballo L, Capriles-Hulett A, Caballero-Fonseca F. Increased total and mite specific immunoglobulin E in patients with aspirin-induced urticaria and angioedema. J Investig Allergol Clin Immunol 2010;20:139-45.

36. Katz Y, Goldberg N, Kivity S. Localized periorbital edema induced by aspirin Allergy 1993;48:366-9.

37. Quiralte J, Blanco C, Delgado J, Ortega N, Alcntára M, Castillo R, et al. Challenge-based clinical patterns of 223 Spanish patients with nonsteroidal anti-inflammatory-drug-induced-reactions. J Investig Allergol Clin Immunol 2007; 17: $182-8$

38. Quiralte J, Avila-Castellano R, Cimbollek S. A phenotype-based classification of NSAIDs hypersensitivity: new patients, new challenges. Allergy 2014;69:814-5.

39. Kowalski ML, Makowska J. Reply: to PMID 24117484. Allergy 2014;69:815-6.

40. Doña I, Blanca-Lopez N, Torres MJ, Gomez F, Fernandez J, Zambonino MA et al. NSAID-induced urticaria/angioedema does not evolve into chronic urticaria: a 12-year follow-up study. Allergy 2014;69:438-44.

41. Sánchez-Borges M, Acevedo N, Vergara C, Jimenez S, Zabner-Oziel P, Monzón $\mathrm{A}$, et al. The $\mathrm{A}-444 \mathrm{C}$ polymorphism in the leukotriene $\mathrm{C} 4$ synthase gene is associated with aspirin-induced urticaria. J Investig Allergol Clin Immunol 2009; 19:375-82.

42. Torres-Galván MJ, Ortega N, Sánchez-Garcia F, Blanco C, Carrillo T, Quiralte J. LTC4-synthase A-444C polymorphism: lack of association with NSAID-induced periorbital angioedema in a Spanish population. Ann Allergy Asthma Immunol 2001;87:506-10

43. Vidal C, Porras-Hurtado L, Cruz R, Quiralte J, Cardona V, Colás C, et al. Association of thromboxane A1 synthase (TBXAS1) gene polymorphism with acute urticaria induced by nonsteroidal anti-inflammatory drugs. J Allergy Clin Immunol 2013;132:989-91.

44. Kidon MI, Kang LW, Chin CW, Hoon LS, See Y, Goh A, et al. Early presentation with angioedema and urticaria in cross-reactive hypersensitivity to nonsteroidal antiinflammatory drugs among young Asian, atopic children. Pediatrics 2005;116:675-80.

45. Sanchez-Borges M, Capriles-Hulett A, Capriles-Behrens E, Fernandez-Caldas E. A new triad: sensitivity to aspirin, allergic rhinitis, and severe allergic reaction to ingested aeroallergens. Cutis 1997;59:311-4.

46. Quiralte J, Blanco C, Castillo R, Delgado J, Carrillo T. Intolerance to nonsteroidal anti-inflammatory drugs: results of controlled drug challenges in 98 patients. J Allergy Clin Immunol 1996;98:678-85.

47. Torres MJ, Barrionuevo E, Kowalski ML, Blanca M. Hypersensitivity reactions to nonsteroidal anti-inflammatory drugs. Immunol Allergy Clin North Am 2014;34: 507-24.

48. Woessner KM, Castells M. NSAID single-drug-induced reactions. Immunol Allergy Clin North Am 2013;33:237-49.

49. Kowalski ML, Bienkiewicz B, Woszczek G, Iwaszkiewicz J, Poniatowska M. Diagnosis of pyrazolone drug sensitivity: clinical history versus skin testing and in vitro testing. Allergy Asthma Proc 1999;20:347-52.

50. Quiralte J, Blanco C, Castillo R, Ortega N, Carrillo T. Anaphylactoid reaction due to nonsteroidal anti-inflammatory drugs: clinical and cross-reactivity studies. Ann Allergy Asthma Immunol 1997:78:293-6.

51. Chaudhry T, Hissaria P, Wiese M, Heddle R, Kette F, Smith WB. Oral drug challenges in non-steroidal anti-inflammatory drug-induced urticaria, angioedema and anaphylaxis. Intern Med J 2012;42:665-71.

52. Canto MG, Andreu I, Fernandez J, Blanca M. Selective immediate hypersensitivity reactions to NSAIDs. Curr Opin Allergy Clin Immunol 2009;9:293-7.

53. Kowalski ML, Woszczek G, Bienkiewicz B, Mis M. Association of pyrazolone drug hypersensitivity with HLA-DQ and DR antigens. Clin Exp Allergy 1998; 28:1153-8.

54. Hammond TG, Meng X, Jenkins RE, Maggs JL, Santoyo Castelazo A, Regan SL, et al. Mass spectrometric characterization of circulation covalent protein adducts derived from a drug acyl glucuronide metabolite: multiple albumin adductions in diclofenac patients. J Pharmacol Exp Ther 2014;350:387-402.

55. Osaki F, Goto T, Lee SH, Oe T. Predicted multiple selected reaction monitoring to screen activated drug-mediated modifications on human serum albumin. Anal Biochem 2014:449:59-67.

56. Czerniawska-Mysik G, Szczeklik A. Idiosyncrasy to pyrazolone drugs. Allergy 1981;36:381-4

57. Brockow K, Garvey LH, Aberer W, Atanaskovic-Markovic M, Barbaud A, Bilo $\mathrm{MB}$, et al. ENDA/EAACI Drug Allergy Interest Group. Skin test concentrations for systemically administered drugs - an ENDA/EAACI Drug Allergy Interest Group position paper. Allergy 2013;68:702-12

58. Gómez E, Blanca-López N, Torres MJ, Requena G, Rondon C, Canto G, et al. Immunoglobulin E-mediated immediate allergic reactions to dipyrone: value of basophil activation test in the identification of patients. Clin Exp Allergy 2009; 39:1217-24.

59. Zembowicz A, Mastalerz L, Setkowicz M, Radziszewski W, Szczeklik A. Histological spectrum of cutaneous reactions to aspirin in chronic idiopathic urticaria. J Cutan Pathol 2004:31:323-9.

60. Caimmi S, Caimmi D, Bousquet PJ, Demoly P. How can we better classify NSAID hypersensitivity reactions? Validation from a large database. Int Arch Allergy Immunol 2012;159:306-12.

61. Kowalski ML, Makowska J. Seven steps to diagnosis of NSAIDs hypersensitivity. Allergy Asthma Immunol Res 2015;4:312-20.

62. Blanca-Lopez N, Torres MJ, Doña I, Campo P, Rondón C, Seoane Reula ME et al. Value of the clinical history in the diagnosis of urticaria/angioedema induced by NSAIDs with cross-intolerance. Clin Exp Allergy 2013;43:85-91.

63. Viola M, Rumi G, Valluzzi RL, Gaeta F, Caruso C, Romano A. Assessing potential determinants of positive provocation tests in subjects with NSAID hypersensitivity. Clin Exp Allergy 2011;41:96-103.

64. Stevenson DD, Kowalski ML. An epidemic of over diagnosing drug allergies. Allergy Asthma Proc 2014;35:92-4.

65. Kowalski ML, Makowska J. Use of nonsteroidal anti-inflammatory drugs in patients with aspirin hypersensitivity: safety of cyclo-oxygenase-2 inhibitors. Treat Respir Med 2006;5:399-406. 
66. Asero R, Bavbek S, Blanca M, Blanca-Lopez N, Cortellini G, Nizankowska-Mogilnicka E, et al. Clinical management of patients with a history of urticaria/angioedema induced by multiple NSAIDs: an expert panel review. Int Arch Allergy Immunol 2013;160:126-33.

67. Sanchez Borges M, Capriles-Hulett A, Caballero-Fonseca F, Perez CR. Tolerability to new COX-2 inhibitors in NSAID-sensitive patients with cutaneous reactions. Ann Allergy Asthma Immunol 2001;87:201-4.

68. Asero R. Leukotriene receptor antagonists may prevent NSAID-induced exacerbations in patients with chronic urticaria. Ann Allergy Asthma Immunol 2000;85: $156-7$.

69. Slowik SM, Slavin RG. Aspirin desensitization in a patient with aspirin sensitivity and chronic idiopathic urticaria. Ann Allergy Asthma Immunol 2009; 102:171-2.
70. White AA, Stevenson DD, Woessner KM, Simon RA. Approach to patients with aspirin hypersensitivity and acute cardiovascular emergencies. Allergy Asthma Proc 2013;34:138-42.

71. McMullan KL, Wedner HJ. Safety of aspirin desensitization in patients with reported aspirin allergy and cardiovascular disease. Clin Cardiol 2013;36:25-30.

72. Blanca-López N, Barrionuevo E, Andreu I, Canto MG. Hypersensitivity reaction to nonsteroidal anti-inflammatory drugs: from phenotyping to genotyping. Curr Opin Allergy Clin Immunol 2014;14:271-7.

73. Ayuso P, Blanca-López N, Doña I, Torres MJ, Guéant-Rodríguez RM, Canto G, et al. Advanced phenotyping in hypersensitivity drug reactions to NSAIDs. Clin Exp Allergy 2013;43:1097-109.

74. Perkins JR, Sanak M, Canto G, Blanca M, Cornejo-García JA. Unravelling adverse reactions to NSAIDs using systems biology. Trends Pharmacol Sci 2015;36:172-80. 